\title{
Consort hypersensitivity pneumonitis
}

\author{
R. Merget*, I. Sander*, S. Ewig ${ }^{\#}$, J. Sennekamp ${ }^{\star}$ and T. Bruening*
}

ABSTRACT: To date, there is little information in the literature that hypersensitivity pneumonitis due to birds may occur without direct contact to birds.

A 62-yr-old pensioner developed mild flu-like symptoms, fatigue and polyuria several hours after each meeting with his new female partner, either in hotels or his apartment. After divorcing from her ex-husband, who was a canary fancier, the female had moved into a bungalow $\sim 6$ months earlier. When the couple met for the first time at the bungalow, the patient's symptoms worsened and he developed shortness of breath. The patient had never entered the bird house or the married couple's house.

Hypersensitivity pneumonitis was demonstrated by chest radiography, computed tomography, a restrictive ventilatory defect, decreased diffusion capacity and hypoxaemia after physical exercise. Sensitisation to canaries was shown by immunoassays. Canary antigens were detected by a polyclonal immunoassay at different locations of the married couple's house and the female's bungalow, where no birds had ever been kept.

In conclusion, hypersensitivity pneumonitis should be recognised as a further consort disease, i.e. a disease that can be transmitted by partners.

KEYWORDS: Birds, diagnosis, dose-response, hypersensitivity pneumonitis, partner

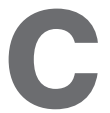
onsort contact dermatitis is a well established term that refers to contact dermatitis after contact (not necessarily sexual) to partners [1]. The present case study reports a further consort disease that affects the lungs. The patient reported herein gave his permission for his case to be studied.

\section{CASE REPORT}

A 62-yr-old nonsmoking male, a former medical doctor, met and fell in love with a female whom he met occasionally in his apartment or hotels. Besides seasonal rhinoconjunctivitis the patient was healthy until $\sim 4$ months after the first meeting with the female when he experienced fever, flu-like symptoms, fatigue and polyuria with a latency of some hours after each meeting. The same symptoms, but much more severe, together with shortness of breath on exertion occurred after the couple had met in the bungalow where the female lives. She had bought the bungalow 6 months earlier following her divorce. She had moved clothes and furniture from her marital home to the bungalow. The patient suffered further recurrence of the symptoms after spending a night in the bungalow. A chest radiograph, which was normal 4 yrs earlier, showed an area of increased opacity in the right lower lobe and discrete ill defined nodular opacities with ground-glass appearance in both lungs (fig. 1a). Medication containing clarithromycine appeared to improve symptoms, but the patient sought medical advice from a pneumologist. A mild restrictive ventilation pattern with a total lung capacity (TLC) of $87 \%$ predicted was measured. The single-breath diffusing capacity of the lung for carbon monoxide (DL,CO) was reduced to $49 \%$ pred. Prednisolone, $60 \mathrm{mg}$ per day, was prescribed. When the patient experienced a further episode of bungalow-related severe symptoms in spite of steroid medication, a more intense evaluation was initiated. Computed tomography of the thorax showed multiple intralobular ill defined nodules with a minor mosaic ground-glass pattern, predominant in the lower lobes, possibly with air trapping (fig. 1b). Lung function was unchanged, but treadmill exercise revealed a fall of partial pressure of oxygen from 83 to $65 \mathrm{mmHg}$ (11.1 to $8.7 \mathrm{kPa}$ ). Bronchoalveolar lavage demonstrated lymphocytosis (55\% lymphocytes) with a decreased CD4/CD8 ratio (0.96) and an increased percentage of CD57-positive lymphocytes (65\%). The patient demonstrated no immunoglobulin (Ig)G antibodies to various moulds, budgerigar, pigeon, duck and goose. However, slightly
AFFILIATIONS

${ }^{*}$ Research Institute of Occupational Medicine, German Social Accident Insurance (BGFA), Ruhr University, \#Augusta Hospital, Thorax Centre of the Ruhr Area, Bochum, and "Laboratory for Allergic Diseases of the Malteser Hospital, Bonn, Germany.

CORRESPONDENCE

R. Merget

BGFA

Bürkle-de-la-Camp-Platz 1

D-44789 Bochum

Germany

Fax: 492343024542

E-mail: merget@bgfa.de

Received:

August 192008

Accepted after revision:

December 122008

STATEMENT OF INTEREST

None declared. 

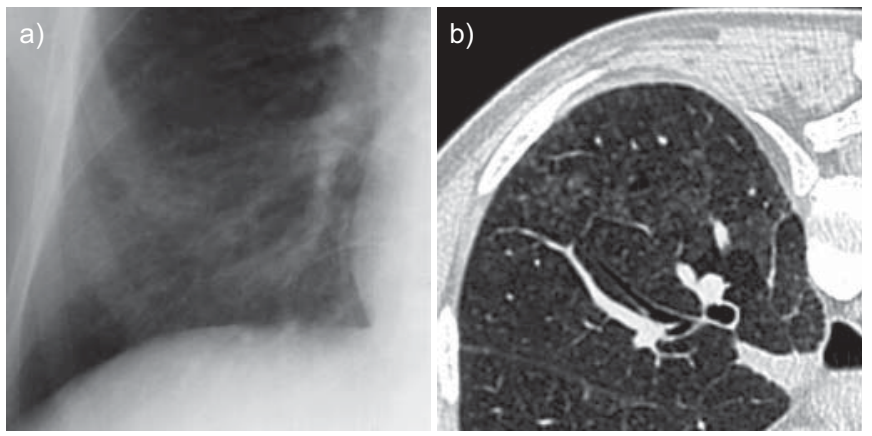

FIGURE 1. a) Chest radiograph of the patient after initial symptoms in July 2007, demonstrating an area of increased opacity in the right lower lobe. b) Highresolution computed tomography of the thorax at the time of diagnosis, November 2007, showing multiple intralobular ill-defined nodules with minor mosaic groundglass pattern, possibly with air trapping.

increased levels of IgG antibodies to canary were measured by solid phase ELISA and to canary and cockatiel by the indirect immunofluorescence test on fixed sections of avian intestine [2]. Total $\operatorname{IgG}, \operatorname{IgA}$ and $\operatorname{IgM}$ levels were within reference values. No further causes of an interstitial lung disease (infectious or immunological) were found, but there was a history of previous infection with Chlamydia pneumoniae (without change of IgG or IgA concentrations) within 2 months. Further investigation revealed that the female's exhusband was a canary fancier. In total, up to 200 animals were kept in a bird house near the ex-married couple's house, but never in the female's bungalow. A diagnosis of hypersensitivity pneumonitis (HP) due to canary was made and therapy with prednisolone continued.

\section{FURTHER IMMUNOLOGICAL EVALUATION AND EXPOSURE ASSESSMENT}

Approximately $1 \mathrm{yr}$ after the appearance of symptoms and after extensive cleaning of the bedroom in the bungalow, the patient spent another night in the bungalow. As the patient's symptoms redeveloped, he contacted the Research Institute of Occupational Medicine (German Social Accident Insurance (BGFA), Ruhr University, Bochum, Germany) to perform an environmental survey and to possibly detect an antigen source. Elevated specific IgG concentrations to canary feathers (e201) were reproduced in the patient's serum ( $39 \mathrm{mg}$ of antibody $\cdot \mathrm{L}^{-1}$ ) by ImmunoCAP (Phadia, Uppsala, Sweden). Furthermore, IgG antibodies to budgerigar feathers $\left(\mathrm{e} 78,41 \mathrm{mg}\right.$ of antibody $\left.\cdot \mathrm{L}^{-1}\right)$, parrot feathers $\left(\mathrm{e} 213,53 \mathrm{mg}\right.$ of antibody $\left.\cdot \mathrm{L}^{-1}\right)$, cockatiel feathers $\left(\mathrm{e} 196,27 \mathrm{mg}\right.$ of antibody $\left.\cdot \mathrm{L}^{-1}\right)$ and pigeon droppings $(\mathrm{e} 7,55 \mathrm{mg}$ of antibody $\cdot \mathrm{L}^{-1}$ ) were increased. Cross-reactivity of $\operatorname{IgG}$ antibodies could be shown by reduced binding to canary feathers after pre-binding the patient's serum to ImmunoCAP with budgerigar feathers, parrot feathers and pigeon droppings (49\%, $72 \%$ and $32 \%$ reduction, respectively). To investigate a potential contamination with canary antigens, the patient was instructed how to sample dust on glass-fibre filters using a vacuum cleaner with sampling nozzles (ALK Technologies, Horsholm, Denmark). Dust was collected from different parts of the bungalow and the ex-married couple's home for $\sim 4 \mathrm{~min}$ and $2 \mathrm{~m}^{2}$ at each location. The dust on the glass-fibre filters was extracted, lyophilised, dissolved in $0.5 \mathrm{~mL}$ PBS and used as inhibitor $(10 \mu \mathrm{L})$ with the patient's serum (diluted 1:100) and canary ImmunoCAPs. Some locations, both in the bungalow and the ex-married couple's house, were still contaminated with canary antigens (table 1).

When the patient abstained from entering the bungalow for 3 months his IgG level to canary feathers fell from 39 to $27 \mathrm{mg}$ of antibody $\cdot \mathrm{L}^{-1}$ and he was symptom-free without steroid medication. Lung function continued to show mild restriction with a TLC of $85 \%$ pred and DL,CO was $63 \%$ pred. Pulmonary exercise testing yielded a peak oxygen uptake of $70 \%$ pred at a workload of $73 \%$ pred. Oxygen desaturation during exercise was no longer apparent.

\section{DISCUSSION}

There is no doubt that the patient had HP. Sensitisation to canary is demonstrated by medical history and in vitro testing. The patient reported symptoms that are typical for acute HP (fever, flu-like symptoms, fatigue and shortness of breath) but also polyuria. It may be speculated that polyuria was a result of an acute pressure overload of the right heart, but the authors found no association of this observation with HP in the literature.

$\mathrm{HP}$ due to canary is extremely rare [3]. Cross-reactivity between bird antigens is well-known [2] and was demonstrated using the patient's IgG. Neither the patient nor his female partner were exposed to other birds. Making a diagnosis of HP due to such a rare antigen is important for the interpretation of the present case as it underlines that the

TABLE 1 Canary antigen measurements at different locations by polyclonal immunoglobulin (Ig)G inhibition immunoassay

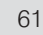

907

Blanket on sofa in ex-married couple's house

Carpet in bedroom of ex-married couple's house

Walk-in cupboard/clothes in bedroom of ex-married couple's house

Guest room floor in female's bungalow

Bureau floor in female's bungalow

Bedroom floor in female's bungalow ${ }^{\S}$
1503

78

85

478

156
81

84

41

8

59

84

0

\#: high inhibition corresponds to high-antigen concentrations; ": the bird house is situated outside the ex-married couple's house, has plain floor surfaces and had been cleaned before sampling; ${ }^{+}$: after extensive cleaning; ${ }^{\text {s. }}$ after extensive cleaning and use of a high-efficiency particulate air filter. 
patient indeed acquired sensitisation by indirect contact. It cannot be fully excluded that sensitisation to canary occurred earlier. The patient reported that his parents had kept a canary while he was living in another town as a student, and also later for 1 or 2 yrs. However, he rarely saw his parents at home and had no direct contact with the bird. As the symptoms developed when the patient was in close proximity to the present antigen exposure, it is highly probable that sensitisation occurred due to recent exposure.

The measurements of canary antigens demonstrate that antigen can be transported to a relevant degree and may sensitise persons who are not aware of exposure. The presentation of symptoms at locations outside the bungalow proves that the antigen was transported on her hair or clothes, whereas antigen in the bungalow may also originate from contaminated furniture. In addition, symptoms occurred with a latency of some hours between exposure and symptoms so that the allergen source was not obvious. In the present case it took several months to make the diagnosis, although the patient was a medical doctor.

Whereas it is well-known that the transfer of allergens in immunoglobulin E-mediated disease by kissing may cause allergic reactions in sensitised subjects [4], the induction of immunoglobulin E-mediated sensitisation by partners has not been shown, and there are only two cases of hypersensitivity pneumonitis in spouses of bird fanciers [5]. Further case reports without involvement of partners indicate that hypersensitivity pneumonitis may develop in subjects with minimal exposure $[6,7]$. The present case corroborates these rare observations and adds to present knowledge that allergen transported by hair or clothes may induce hypersensitivity pneumonitis in susceptible subjects.

\section{REFERENCES}

1 Fisher AA. Consort contact dermatitis. Cutis 1979; 24: 595596, 668.

2 Sennekamp J, Lange G, Nerger K, Berdel D, Meier-Sydow J. Human antibodies against antigens of the sparrow, blackbird, weaver finch, canary, budgerigar, pigeon and hen using the indirect immunofluorescent technique. Clin Allergy 1981; 11: 375-384.

3 Sennekamp H-J. Extrinsic Allergic Alveolitis: Hypersensitivity Pneumonitis. Munich, Dustri-Verlag, 2004.

4 Wüthrich B, Däscher M, Borelli S. Kiss-induced allergy to peanut. Allergy 2001; 56: 913.

5 Riley DJ, Saldana M. Pigeon breeders' lung. Subacute course and the importance of indirect exposure. Am Rev Respir Dis 1973; 107: 456-460.

6 Greinert U, Lepp U, Becker WM. Bird keeper's lung without bird keeping. Eur J Med Res 2000; 5: 124.

7 Schreiber J, Knolle J, Sennekamp J, et al. Subacute occupational hypersensitivity pneumonitis due to low level exposure to diisocyanates in a secretary. Eur Respir J 2008; 32: 807-811. 